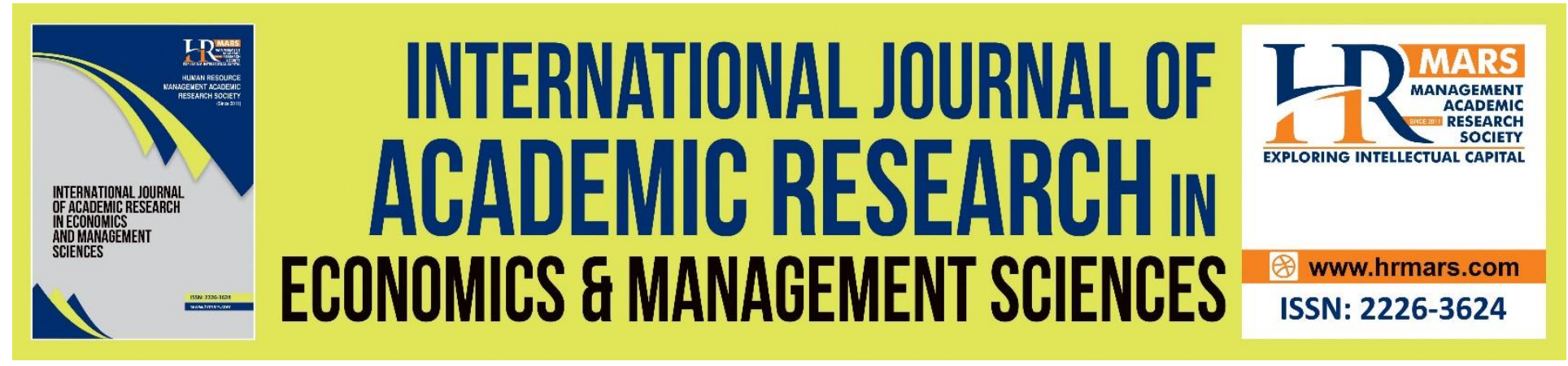

\title{
The Ethical Decision-Making Practices among Malaysian Consultant Quantity Surveyor
}

Nor Atikah Hashim, Ismi Arif Ismail, Zohara Omar, Khairuddin Idris

To Link this Article: http://dx.doi.org/10.6007/IJAREMS/v10-i3/10427

DOI:10.6007/IJAREMS/v10-i3/10427

Received: 01 June 2021, Revised: 05 July 2021, Accepted: 06 August 2021

Published Online: 12 August 2021

In-Text Citation: (Hashim et al., 2021)

To Cite this Article: Hashim, N. A., Ismail, I. A., Omar, Z., \& Idris, K. (2021). The Ethical Decision-Making Practices among Malaysian Consultant Quantity Surveyor. International Journal of Academic Research in Economics and Managment and Sciences, 10(3), 106-121.

Copyright: (C) 2021 The Author(s)

Published by Human Resource Management Academic Research Society (www.hrmars.com)

This article is published under the Creative Commons Attribution (CC BY 4.0) license. Anyone may reproduce, distribute, translate and create derivative works of this article (for both commercial and non-commercial purposes), subject to full attribution to the original publication and authors. The full terms of this license may be seen at: http://creativecommons.org/licences/by/4.0/legalcode

Vol. 10, No. 3, 2021, Pg. 106 - 121

http://hrmars.com/index.php/pages/detail/IJAREMS

JOURNAL HOMEPAGE

Full Terms \& Conditions of access and use can be found at

http://hrmars.com/index.php/pages/detail/publication-ethics 


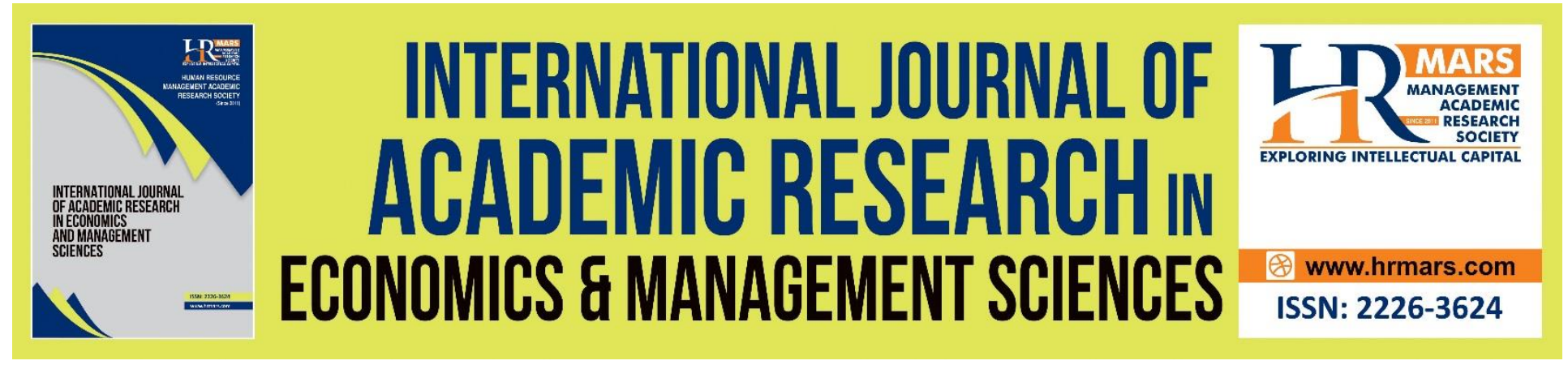

\title{
The Ethical Decision-Making Practices among Malaysian Consultant Quantity Surveyor
}

\author{
Nor Atikah Hashim, Ismi Arif Ismail, Zohara Omar, Khairuddin \\ Idris
}

Department of Professional Development and Continuing Education, Faculty of Educational Studies, Universiti Putra Malaysia, 43400 UPM Serdang, Selangor, Malaysia

Email: atiqmy@gmail.com

\begin{abstract}
Ethical decision-making refers to the process of evaluating and choosing among alternatives in a manner consistent with ethical principles. Ethical decision-making (EDM) expertise is required for consultant quantity surveyors (CQSs) to perform their duties effectively and to protect the client's interests in the construction project. Therefore, as professionals in the construction industry, the CQSs must develop strategies to prevent corrupt practices when dealing with EDM. Thus, this study aimed to investigate ethical decision-making among Malaysian consultant quantity surveyors. Therefore, a qualitative research methodology was selected to gain more detailed and valid descriptions of the EDM phenomenon, through in-depth interviews. Results showed that several issues and parties are responsible for unethical experiences. Findings indicate that CQSS learn through experiential learning and become experts with EDM in professional practice when they intuitively make ethical decisions.
\end{abstract}

Keywords: Ethical Decision-Making, Professional Practice, Experiential Learning, Intuition, Integrity.

\section{Introduction}

The issue of professional ethics in the construction industry has gotten a lot of attention recently. Corrupt tendering practices, a lack of quality in construction work, harmful safety standards, payment problems, corruption (Monteiro et al., 2020; Yap et al., 2020), and, most importantly, a lack of public accountability for money spent on public buildings and infrastructure are common barriers to its resolution. It is critical for all construction teams, including those in professional firms such as architectural, engineering, and quantity surveying firms, as well as contractors and suppliers, to stay in business and obtain work contracts. When a company pays to obtain a contract based on business sustainability, this is an example of a corrupt culture. Business sustainability entails obtaining a consistent flow of projects to cover a company's overhead. It is also regarded as an indicator of a company's good reputation and performance. Sound ethical principles are essential for a professional firm to establish a reputable name in the industry and 
to sustain the business. Profit is the primary motivator for people who conduct business. Most construction teams, such as consultation and contractor teams, are looking to increase their profit to sustain their business, and some are motivated by a desire to get rich quickly. When money, power, and greed take control of human decisions, ethics problems arise. Professional ethics are critical in the construction industry, and professionals must make practical and fair decisions in this complex environment to maintain their professional ethics. The CQS experienced varied complexities and faced competition from other construction professionals and they had procedures to safeguard the survival of the profession (Wao \& Flood, 2016).

Ethical decision-making (EDM) has long been studied, both philosophically and theologically, and across a wide range of disciplines such as business, medicine, athletics, and art (Lehnert et al., 2014). Professionals are required to have an EDM process, but many do not. Ethical issues in the construction industry that lead to corruption have recently been studied by several researchers, including (Yap et al., 2020; Lee and Foo, 2020; Chamikara et al., 2018; Le et al., 2018; Wao and Flood, 2016). Only one study (Wao \& Flood, 2016) focuses specifically on the quantity surveyors profession, but it does not take place in Malaysia. Current Malaysian studies of corruption (Yap et al 2020) and decision-making (Lee \& Foo, 2020) focused on construction project practitioners. There is a need for specific EDM studies for the Quantity Surveying profession because they are the key person dealing with financial matters in construction projects and are vulnerable to integrity issues such as corruption. Because of corruption in the construction industry, Monteiro et al (2020) suggest structural changes in strategies to prevent corrupt practices and extend the literature deepening on the understanding of this disruptive phenomenon.

According to the findings of a survey conducted by Abdul-Rahman et al (2010), 74.2 percent of construction industry participants agree that unethical behavior is prevalent in the Malaysian construction industry. It is especially common in public projects, where the lowest-bidder contractors and suppliers are frequently awarded the tender. The evidence of relatively highlevel corruption incidents in Malaysia's construction industry is comparable to the findings of a corruption investigation conducted by Transparency International (2019), a global anticorruption coalition. The Society of Consultant Surveyors recognizes that one of the primary reasons people rely on professional bodies is to uphold ethical principles. According to Latham and Whyte, (1994); Egan (2001); Christabel and Vincent (2003); Man-Fong Ho (2011); and the Construction Industry Review Committee (2001), unethical behavior by construction industry professionals has harmed public trust in and respect for the dignity of their professional competence. Unethical issues have a significant impact on the construction industry. According to Malaysian construction industry reports, 17.3 percent of 417 government projects were deemed 'sick' (Adnan et al., 2012). The unethical behavior of construction project teams has an impact on the quality of the projects (Adnan et al., 2012; Abdul-Rahman et al., 2010). The need for research on professional practice experience in EDM is critical for the long-term development of the country and the profession's economic and social aspects. As a result, this study will provide a clear picture of the current state of quantity surveying practice in performing EDM.

\section{Literature Review}

Ethical and responsible behavior cannot be attributed solely to individual virtue; rather, it is the result of a complex interplay of personalized and contextual factors, both internal and external to an organization (O'Leary \& Stewart, 2007; Meyers, 2004). Understanding how EDM is 
structured in the context of CQS practice (in-context) from a human resource development perspective is critical to the profession's growth and sustainability. Much of the research conducted by proponents of practice-based approaches, such as communities of practice and situated learning, emphasizes the embedded nature of the practice. Construction is one of the most dynamic, risky, and difficult industries to work in. However, the industry has a poor reputation for risk management, with many large projects failing to meet deadlines and budgets (Mills, 2001). In Malaysia's construction industry, ethical standards among construction professionals are regarded as below average (Abdul-Rahman et al., 2010). The practice of ethics and EDM is critical for construction professionals, but many factors influence their behavior and conduct. Yap et al., (2020) examines the influence of corruption on project outcomes, explores the causes of corruption, and evaluates anti-corruption measures in Malaysia. They found that, in the Malaysian construction industry, negative encouragement is more likely to induce corruption, followed by the nature of the construction industry, and flawed regulatory systems. From start to finish, the construction process is complex and involves a large number of people with varying skills. It also entails dealing with new design and construction issues, as well as making numerous assumptions about factors such as weather, site conditions, interest rates, and labor and material availability. Many external and uncontrollable factors contribute to these complexities.

Risk management is part of the scope of work for CQSs in carrying out their professional duties and responsibilities. In CQS practice, intuition, expert skill, and judgment will always play a role in decision-making (Khairani, 2012). Intuitions are defined as 'effectively charged judgments that arise through rapid, non-conscious and holistic associations' (Dane $\&$ Pratt, 2007). Associations above and below the level of conscious awareness can include the level of danger or opportunity and the feelings of elation or disappointment that a pattern of experience may have induced in past successes or failures. One implication of this assertion is that memories may be embodied in a resonating emotion as somatic markers that can be reactivated in a context-congruent situation (Bechara \& Martin, 2004). Tacit knowledge involves theoretical knowledge as well as intuition and is developed over time through practice (Eraut, 2000). According to Lave and Wenger (1991), a learning process is a standing activity that has a centralized feature where the process is known as legitimate peripheral participation. Individuals who want to learn something need to be involved in a community practicing specific knowledge and skills (Kimble et al., 2008, p. 58). Therefore, practice is constitutive for this understanding of ethical knowledge and the CQSs achieve EDM through a learning experience in real-life situations. Learning is a continuous process based on experience (Kolb, 1984). The situated learning concept is known as the supervisory process to social practice or practice and is a process of preparation for most professions (Lave \& Wenger, 1991; Wenger, 1999; Garvey et al., 2018). The Dreyfus model is a general, phenomenological explanation of how people learn certain skills. According to Dreyfus and Dreyfus (1986), an explicit rule-following takes place at an essential, not more advanced skill level. A more advanced skill level is characterized by experience-based expertise that cannot be articulated entirely in the form of rules. In their study of skill acquisition from various areas of the profession, Dreyfus and Dreyfus (1986) argue that skill acquisition in each new area typically proceeds through the five-skill levels of novice, advanced beginner, competent, proficient, and expert. However, not all practitioners achieve the expert level. In this study, the researcher focuses on the expert level only, which is the level of the CQS, and how they achieve EDM with 
experience-based expertise. Evaluating thinking and conduct and eventually altering them can finally solve a problem in a satisfying, ethically competent manner.

\section{Method}

The qualitative research method was used in this study, which focuses on understanding the essence of the experience faced by CQSs in EDM through their professional practice. Due to current issues and research gaps, there is a need to describe the essence of these lived phenomena. The current study looks at several CQSs who have had similar EDM experiences in their professional practice. How does CQS use EDM at work? Because learning occurs within a community of practice, the researcher applied situated learning theory to investigate the meanings and experiences shared by CQSs. Experiential learning theory was also used by the researcher to explain the phenomenon in depth. It is critical to gain a better understanding of how CQSs learn about EDM and make ethical decisions in their professional lives. Because the researcher is interested in learning more about a few people in-depth, the qualitative approach is used. Concerning practice, the researcher looks into the participants' situated learning experiences, which are best explored using qualitative research where data is more enriching and detailed. Qualitative research does not put a theory to the test, conduct experiments, or measure anything (Merriam \& Tisdell, 2016). The theory is used to thoroughly explain this lived phenomenon to comprehend the consequences of the action. In this qualitative study, the researcher used purposeful sampling. Individuals and sites involved in the study were chosen because they can purposefully inform an understanding of the research problem and the study's central phenomenon (Creswell \& Poth, 2018). Participants were restricted to Consultant Quantity Surveyors (CQSs) who were members of a quantity surveying organization, namely the Board of Quantity Surveyor Malaysia (BQSM) and the Royal Institution of Surveyors Malaysia (RISM) (RISM). Five participants from an active consulting firm were interviewed. The participants' ages ranged from 50 to 62 . The participants who were chosen had more than 15 years of experience as CQSs. The researcher used her position as a QS to gain access to and consent from the participants. EDM is a sensitive issue for CQSs and is not openly or freely discussed. All participants agreed to the researcher recording the interview. The researcher went over the interview, data management, data analysis, and reporting processes in great detail. The researcher informed the participants about the study's ethical aspects, which were stated in the consent form. This process assisted in clarifying the researcher's position and expressing the value of the participant's involvement in the study and their voluntary consent to participate in the research. To obtain the research findings, the thematic analysis approach was used for data analysis. Humans were the study's research subjects and data source. To avoid unethical treatment of human subjects, ethical considerations were carefully addressed.

\section{Results}

\section{EDM in Professional Practice}

The research looked at how the CQS handles unethical situations and employs EDM in professional practice. Thus, to determine whether a CQS'S EDM in practice has a specific basis, the researcher asked the participants to share their experiences of EDM in practice. According to the results, several issues and parties are responsible for unethical experiences. However, the most important question is how the CQS reacts to the situation? Do they follow through with it 
or retreat? They cannot change the way people act (dishonesty, corruption, abuse of power), but they can change the way of tackling the problems.

\section{Experience and Intuition}

When asked how consultant quantity surveyors make ethical decisions in professional practice, all participants agreed that skills maneuvering through EDM are based on prior experience. Their intuitions have developed as a result of their personal experience with unethical situations. One participant stated that she is well-trained in this area and that her training experience has given her confidence in EDM. CQSs improve their EDM by gaining practical experience. Experience in practice is essential for CQSs to make ethical decisions. Another participant mentioned that experience and expertise in EDM are important to CQS because they cannot resolve ethical issues unless they are expertly familiar with the rules or know how to achieve a win-win situation between the government, the contractor, and the consultant. Participants' practices have been established within the framework of the ruling, and they would not proceed if there were inappropriate or contradictory issues. Many inexperienced QS, however, are unable to apply EDM due to incompetence with the ruling or a lack of know-how to achieve a win-win situation with the client, consultants, and contractors. If there are issues that cannot be resolved through contractual means, the participant's practices must be based on a reasonable commercial decision that does not jeopardize the contractual position. Another participant agrees that acting professionally is essential for gaining respect from other parties. To maintain the profession's stewardship, EDM must be used at all times. In retrospect, she dictates principal consultants with the client's permission and does so in a professional manner with no intention of belittling anyone, in other words: respect. When something goes wrong, rather than pointing fingers, the participant plays her role by offering advice on how to move forward, accept, and manage. It is not easy and necessitates the understanding of all parties involved. Her experience as a CQS, Project Manager, Superintendent Officer (SO), and SO Representative has helped her develop this skill. Another participant stated that professional practice experience is critical for the success of CQS because many things cannot be dissolved through a contract. After all, it must be based on a reasonable commercial decision that does not jeopardize the contractual position. EDM for the CQS is aided by knowledge and experience in contract management. One participant added, "There are many reasons this thing can be done... is to work within the ambits of the ruling that called "justifications" and reasonableness of professional exercise." Furthermore, as a professional, one participant usually makes decisions based on intuition, which they claim is gained through professional practice experience. When asked if they consult any theoretical principles before making a decision, the participants admit that they do not consult any code of ethics in practice, instead of relying on their experience in conducting their business. This mirrors another participant's practice where they follow the rules of company policy but are already trained. The 'know-how' concept is crucial for decision-making by experts, because it shows the conduct of the expert and whether or not they can make an ethical decision based on the experience they have gained in professional practice. The participant claims that they know what is right or wrong in practice and that it is up to them to decide. Professional practice experience is therefore crucial for the CQS to make an ethical decision. The more experience they gain, the more experts they become. As a result, they become experts and meld with their intuition. 


\section{Adherence to Duty of Care}

The CQS, as the cost consultant, must adhere to the professional duty of care as stipulated under the code of professional conduct in the Quantity Surveying Rules, under section 26 of the Quantity Surveyors Act 1967. There are several sets of principles that the CQS must follow to practice stewardship. Mason (2009) defines ethical behavior and practices as adhering to the following ethical principles: honesty, fairness, fair reward, dependability, integrity, objectivity, and accountability. The results of the interviews were comparable. The CQSs demonstrate their expert knowledge of EDM by carrying out their duties by the following ethical principles:

\section{Integrity}

Integrity is defined as the value of being truthful and having strong moral principles - moral worthiness. Mason (2009) defined integrity as considering the public's interest, particularly those who will use or gain interest in a future project. Several issues regarding the lack of integrity faced by CQSs in practice were raised by participants. The first issue was bureaucracy in government projects. It crosses many levels and sections, taking more time and necessitating a response to various needs expressed by the participant. When information passes through multiple bureaucratic levels and people (technical or non-technical), it undergoes many changes, resulting in a messy and unnecessary procedure that delays project implementation. The participant also explains that contract management and project procurement are becoming incompatible across projects because contract documents between the federal and state governments differ based on project needs, even though all government projects use the same Public Works Department contract (PWD). According to several participants, the main issue is integrity, as well as a lack of supervision on-site, while corruption occurs at all levels of the government agency. The participants believe that the 'design and built contract' makes it easy to conceal things. Then there was the problem of corruption in government projects. The participant expressed her dissatisfaction with the projects, claiming that "there are a lot of loopholes." The issue is a lack of awareness among the construction teams. It was not regarded as a serious issue. Similar to another participant's experience, delays exacerbate the construction project's problems. Clients, for example, delaying tender awarding to the contractor, clients delaying payments to the contractor, and consultants - architects, engineers, and others - delaying the verification of variation orders to the contractor. This phenomenon contributes to project delays, increasing cost and time; as a result, the overall completion and cost projection will be large. One participant stated that as the CQS, he always advised his clients to pay the contractor as specified in the contract by using proven materials such as meeting minutes and always by writing a reminder letter. The sending of a letter with meeting minutes attached serves as a reminder to the parties to fulfill their contractual obligations.

Corruption continues because the victim does not report or bring the matter to a judgment because, as one participant stated, reporting or bringing the matter to the legal authorities about the situation would mean that there would be no future jobs. Nobody wants to put their future business and project opportunities in jeopardy. Furthermore, another participant stressed that pointing out their mistakes would result in you being blacklisted and facing other bureaucracies. Victims will find it difficult to run the project smoothly and will jeopardize the project if they report the corruption to the appropriate authority. When asked about EDM issues encountered in professional practice, all participants agreed that they had difficulty dealing with EDM, 
particularly in government projects. These issues have received little attention in private projects because the private sector is more resilient and resistant to integrity issues, particularly when it comes to money. In government projects, participants would always have to deal with issues of integrity, such as changing the specifics in the tender documents to award specific candidates. The unethical experience has also been reported by the other participant, who claims that the contractor was not chosen based on specialization. This scenario sometimes contributes to the non-performance of the contractor, the project being delayed or abandoned. In addition, she added that corruption in the government agency is due to a lack of integrity, which causes unethical practices.

Another issue was cronyism, whereby the person with influence would award tenders to their friends (cronies). Similar to the situation mentioned above, open tenders already have specific candidates to be awarded and the CQS was asked to amend the tender documents in particular so that they could award the projects to their pre-selected candidates. This is also considered to be an abuse of power - the power to corrupt. Participants agreed that dealing with corrupt people in a government project was complicated. They stated that they always take precautions and remind themselves to always advise the client based on the contract. One participant reflected his experience that the contractor has already been chosen by the people in power and wants the participant to appoint those contractors. He said that corruption exists at all levels. The evaluation is based on the term "cable." People with connections are referred to as "cable" in this context. From the participants' point of view, issues of integrity include the amendment of conditions of contracts, leaking of tender estimates, selection of contractors not according to specialization, cronyism and corruption, contributing to increases in project costs due to high tender bidding, and project abandonment due to non-performance by the contractor. These situations cause taxpayer money to be wasted on unnecessary expenses. Therefore, the public cannot benefit from the infrastructure that the government would otherwise provide.

The Superintendent Officer (SO) manages government projects as a representative of the government (client). The SO is typically chosen from among the Public Works Department's senior technical officers. The participants contended that the majority of today's problems with the client's representative (SO) are the result of their incompetence in project management and contract management. According to one participant, the 'design and built contract' is still used as a traditional contract because they do not know the scope of the contract. Even though 'Conditions of contract' (COCs) cannot, by law, be amended, unwanted clauses are deleted as to their preference when the contract is binding. They are creating a lot of illegal procedures that are not contract-based. Another participant stated that this is due to the SO's lack of competence and contractual knowledge. They are not concerned about the consequences of their actions because they think that the government is immune from the legal system. Other participants added that contractors submit claims based on the progress chart, not the physical progress onsite (submit over claim). When she did valuations based on the work done, the price was twice the actual work done. The SO will then inquire as to why the CQSs' payment does not correspond to the progress on the chart, as the contractor claims. She emphasized the importance of being firm and justifying her actions as a CQS. When she prepares payments, she performs a proper evaluation and calculates payment based solely on actual work done, as specified in the bill of quantities. If the project is abandoned, clients will undoubtedly question why a payment was made to incomplete works if it had already been overpaid, and the CQS would never have done 
so. She contended that people in positions of power do whatever they want; that becoming a professional makes it difficult to maintain integrity; and that, with experience and credibility, the situation can be successfully neutralized without violating ethical conduct.

Leaks in tender estimates for government projects are a common unethical issue. The contractors' estimates may have been obtained through bribery or other means. The effect of leaking tender estimates is an increase in tender bidding by the contractor as they attempt to make more profit from the projects. Contractors will bid higher prices if tender estimates are leaked because they are attempting to ask the government for more. According to one of the participants, not all contractors read and comprehend the contract. They are also unfamiliar with the legal terms because the contract is written in both English and Latin. They are concerned with profitability without considering risk. Furthermore, the participant claims that the contractors are unaware of their rights because they are unaware of the consequences and risks of their actions. Most government contractors lose money because they are unaware of their rights, are bullied, and are forced to pay bribes. When they see the potential profit from the project, they become greedy for it without considering the risks they will face. Most of them are 'Alibaba' companies - a Malay term used to describe contractors who pass on projects awarded to other companies. The reason 'Alibaba' companies hand over the projects to legitimate construction companies is that they usually do not have the technical and financial capabilities to undertake the works involved in the contract. This scenario concerns integrity issues, in which contracts are awarded to favored candidates who may have used illegal means to win them.

In terms of integrity, one participant stated that a big company will ensure that its excellent reputation among clients is maintained to secure future jobs. Making ethical decisions is critical to him, not only for company policy but also to maintain his faith and dignity. Being ethical means that some suppliers avoid collaborating, but the participant expressed pride in his practice of upholding integrity. He explained that fellow friends and consultants respected him and sought valuable advice because of his integrity. Because of his integrity, his CQS firm received UNESCO Excellent Services, the only one in the country, and pushed the participant forward to become the best. He stated that, regardless of profession, fellow consultants will show respect once they know that the firm can be trusted and that the work done is solely for the benefit of the project. According to the participant, once respect is earned, the advice given will be listened to and accepted by the respective clients and fellow consultants. He claimed that receiving recognition from an international agency helps him to sustain his practice and continue to serve clients effectively. He stated that the staff is also aware of the UNESCO standards and acts ethically. He finds it easy to train them because he has already established the standards to follow. After office hours, the participant and his staff can only spend time with clients but not with contractors. Integrity can also be gained through role models. The employees will uphold the standards set by their boss. Ethical behavior is critical to an employer's motivation of an employee. Another participant explaining that he leads by example and accepts full responsibility for his actions to maintain the integrity of his practice. He discussed how his company grew from humble beginnings 25 years ago to be named one of the top ten QS companies in Malaysia and awarded the Best QS Company in Malaysia. The company has received ISO certification from Australia, and one of the criteria that must be met is integrity. Another participant, fuelled by enthusiasm, described how he had accomplished his great feat by broadening his scope of work in practice. 
He insisted that integrity is the most important ingredient and that it also contributes to business sustainability.

\section{Accountability and Responsibility}

Accountability is defined as providing information and warning about matters within one's scope of knowledge that have the potential to harm others who may be affected. A warning must be issued in plenty of time for effective action to be taken to prevent losses. The CQSs' responsibility is to ensure that the project is managed following the contract terms. Any advice or decisions they make must be by the terms of the contract. A simple example scenario is one involving a delay and an extension of time. The CQS typically informs the contractors of the number of days the project has been delayed and the implications of liquidated ascertained damages incurred as a result of the delay. This is because any delay without an extension of time will result in these damages: a sum of money that the contractor must pay the client for lost business opportunities as a result of the delay. It is calculated daily and agreed upon between the contractor and the client at the time of contract signing. It cannot, however, be imposed without evidence, justifications, and a warning to the contractor. Everything must be documented, whether in meeting minutes, emails, or memos. Payment delays are common in the construction industry because, in large projects, payment approval involves many stakeholders and bureaucratic processes. The situation is more complicated for government projects, which require multiple levels of processing and approval and take longer to complete due to red tape. For example, approval may need to be granted at a once-a-month committee meeting. If the meeting is adjourned before this is accomplished, the payment approval will have to wait until the next meeting.

One of the ways to deal with obstacles is by securing the client's interest on the terms of the contract, and whatever is done was based on the client's instructions as claimed by the participant. In the same way, the other participant would include a quotation such as "Leave the final decision to you to decide" if the clients wish to change the tender report but insist on disapproving anything if the dispute is found within the scope of the ruling. The CQSs have indicated that they take the same approaches as professionals when dealing with barriers in practice. According to one of the participants' experiences, three qualified contractors are recommended, but the client must make the final decision. As favoritism is a significant unethical practice in the construction industry, the participant will report on the actual situation of the contractor. For the past decade, it has been common practice to appoint trusted friends or colleagues to complete a project. Being held accountable and only reporting the truth demonstrates that CQS adheres to its ethical principles when practicing EDM. To what extent, however, can CQSs tolerate unethical situations? According to participants, as ethical people, they practice EDM based on their beliefs rather than the situations that arise. The CQS would be consistent and would back down if they were unable to remain professional throughout the project. Experts already know what to do and are impartial. Without a doubt, the solutions come to them intuitively. It is the same for another participant, who sees through proper payment preparation and pays based on work done only according to the bill of quantities while adhering to his principle. From the researcher's observations, the CQS is responsible for their work and has a strong sense of responsibility for EDM. 
Honesty and truthfulness have kept a client to be with them for over 10 years as one of the participants added. Another participant expressed being highly particular about her actions in practice. She explained that duty of care is essential for the CQS in EDM. Their duty of care is for the sake of the accuracy of the financial aspect of the project (pricing of material or value of work done) and payment certifications, as well as to the clients. All the participants agreed that being truthful is essential in the process of EDM. They said that, as professionals, they do not betray any of the parties in the contract.

\section{Justification}

Justification is a reason, explanation, or excuse that provides practical, morally acceptable support for behavior, belief, or occurrence. The CQS needs to justify the decisions made through EDM in professional practice. This must also be supported by evidence in writing (in black and white).To safeguard their professions and sense of professionalism, all the participants stressed that any actions or decisions made must have evidence and be recorded in writing. One participant claimed that his clients always want to change the tender report. Tender report should not be done verbally to safeguard his professionalism. Everything should be proven by letter. Another participant had also experienced the same problems, to which he would take the same approach as one of the other participants: preparing a cover letter to protect his professional practice whereby the contents will write on the client's wish to change certain things despite having been advised otherwise. As said by one of the participants, preparing a cover letter is a standard operating procedure to safeguard a CQS's interest. Every CQS should know that this is an important key, he claimed. Another participant said that she always keeps all conversations in writing, whether the conversation is a brief discussion or a telephone call. For every conversation with clients, other consultants, or contractors, she also writes an email to confirm the communication, especially for those involved in the construction contract. While it may look redundant, she expresses the need for any form to prove to be valuable if problems ever arise. Doing this would allow for an ethical decision if something were to come back and become an issue.

A fellow participant stated that she always encounters the same issues with different types of clients. Clients, she claims, always postpone awarding tenders to contractors. As a result, she usually writes a letter to inform and remind the client of upcoming events. The client is then unable to provide an excuse because she has already reminded them. If the client delays the awarding of tenders, the CQS must notify the client. Professionalism must always be maintained, which is why a letter must be written to notify the client if they delay the tender's validation. This would absolve CQS of any responsibility if they were still unable to act. Part of the CQS's responsibilities includes providing appropriate advice to all contract parties. Another participant claims that the Mechanical \& Electrical (M\&E) consultant took a long time to verify the variation order and that CQS's responsibility is only to fill out the variation order form. Even though it is the M\&E's responsibility, CQS must remind them because if they do not verify, CQS will be unable to fill out the form, delaying the progress of the work and the project. With another participant describing the same problem, a reminder letter must be prepared to remind the consultant of their duty as specified in the contract terms. According to the participants, the best method is to prepare a letter containing all of the meeting minutes of the discussion to confirm and remind the consultants of their contractual obligations. A participant added that there is much reason 
this thing can be done, which is to work within the confines of the ruling that was referred to as "justifications" and the reasonableness of professional exercise.

\section{Avoiding Conflict of Interest}

Avoiding conflict of interest is the best solution to any ethical problem. Understanding the interest of all the parties involved in the contract is the best way to avoid conflict of interest. One of the participants highlighted that they avoid meeting with other parties outside office hours. Even if it was necessary, it is only to meet with the management level but all that was possible because the participants have never betrayed them. To determine the essence of what is considered a conflict of interest, experience in practice is crucial. All the participants claimed that, because of their experience, they already know what their contractual obligations are and which conflicts of interest could arise among the parties involved in a project. The participant insisted to secure the client's interest within the contract. She was confident because she said that she is already trained to perform tasks and she performs them through EDM.

All the participants indicated that they always advise the client, consultant, and contractor according to the conditions of the contract. They always think of solutions to avoid conflict of interest. It is difficult to justify a decision if they advise without basis. Construction projects are complicated and involve dealing with complex problems every day. The participants added that only experts and professionals can advise for the benefit of the project without involving personal interests. Avoiding conflict of interest requires several qualities that only experts have. It must be based on their legal experience and understanding of complex legal issues in construction. It is where performing within the ambits of the ruling comes to poised. Arbitration is the best solution for construction disputes because experts in the field can assess the dispute and provide solutions. All the participant were arbitrators so are well versed in the complex issues of construction.

\section{Company Policy}

Company policy plays a vital role in EDM for the CQS. Business sustainability is dependent upon company reputation. The company policy is stringent whereby it does not deal with unethical things and getting or not getting the project is not a matter, explained one participant. He confirmed being firm in the way he constructs EDM in practice. Additionally, the company contract advisor will check for compliance if there was ever any doubt, on top of the company policy and the rules that need to be followed. This matter was agreed upon by a fellow participant. According to the participants, they all have a company policy to obey, and the most reputable company usually hires a legal advisor to advise on contracts, laws, and regulations. This safeguards the professionalism of the CQS by preventing them from making unethical judgments. With the help of a legal advisor, the CQS has proper guidance for EDM. Usually, this is the case for the broader scope of laws and regulations and international laws. All participants stressed that they have a company policy to obey. A company policy also guides them in matters concerning conflict of interest in the construction field.

\section{Conclusion}

Results from the study show that two factors guide CQSs to perform EDM in their professional practice; experience and expert intuitions, and adherence to duty of care as professionals, 
According to the literature, work experience influences EDM in several ways, such as through the experience associated with increased ethical judgment (Valentine \& Rittenburg, 2007, p. 162), and more experienced learners seem to be more ethically concerned and have greater ethical intentions (Eweje \& Brunton, 2010; Valentine \& Rittenburg, 2007). This can be seen in the CQSs incorporating good moral values such as integrity, accountability, truthful self-restraint, honesty, and avoidance of conflict of interest - while performing EDM in practice. This has similarity with findings by Yap et al (2020), that rank the preventive measures, enforcement of the law, regulations, and sanctions, high integrity, and honest construction culture, and effective reporting channel are the highest factor that adheres to corruption. The CQS gained integrity by upholds the standard set by role models. This supports the findings by Mukumbwa \& Muya, (2013), which holds benchmarking best practices in ethics by observing ethics guidelines and following good leadership on ethics.

The participants agreed that experience in professional practice makes them experts in EDM. Thereby, EDM is naturally embedded in their conduct and fosters them to use their intuition in these situations. As noted by Dreyfus and Dreyfus (1986), among others, intuition is a manifestation of expertise and the ability of experts to exercise fast, non-conscious pattern recognition and pattern matching. This finding was also supported by Woiceshyn (2011) in his study of EDM. He found patterns of use of reason and intuition that emerged from comments and process analysis. The result of this study also indicates that the CQS always gives reason and intuitively performed EDM in practice. Expert is 'as one' with their work and intuitively and holistically identify problems, goals, plans, and actions (Dall'Alba \& Sandberg, 2006).

The CQSs are experts in their field and that no unethical circumstances had influenced their EDM. They reported always being aware of such situations and enacting sound judgment without jeopardizing their professionalism. They allocated integrity as their highest value and indicated that they employed it without fear. The participants had vast experiences embedded in their practice and reported that they perform EDM intuitively. Knowledge acquisition evolves through situated learning and experiential learning in professional practice, and that intuition plays an essential role in EDM for CQSs. As CQSs participate in the learning environment (professional practice), they reflect and articulate their knowledge and experience in their performance of EDM. In this study, the provisional quantity surveyors were involved in authentic settings of daily practice, applying knowledge, and making use of EDM in productive ways. This usually requires social interaction and collaboration with the community of practice. However, the transition into the role of the expert occurs when the provisional quantity surveyor gradually moves away from this community to become engaged in more dynamic and complex activities and become a CQS. This process usually occurs unintentionally. Through situated learning, the provisional quantity surveyor is placed in a real situation under the guidance of a superior who allows them to adopt the theory, practical procedures, and skills learned from formal instruction (Lave \& Wenger, 1999; Browne-Ferrigno \& Muth, 2006; Garvey et al., 2014).

They claim that, due to their expertise, they intuitively make ethical decisions because they have already been trained. To pursue an opportunity, an individual must first be able to perceive those opportunities that have potential commercial value and discriminate between those that are worth pursuing and those that are not. Pattern recognition accounts well for the ability of an expert to 'do what normally works' without explicit awareness of the rules of inference being employed in a given situation (Dreyfus \& Dreyfus, 1986) and without thinking consciously about 
action (Crossan et al., 1999). Indeed, such automated processing is one of the defining features of 'expert intuition'. This 'automated expertise' corresponds to 'recognition of a familiar situation and the straightforward but partially subconscious application of previous learning related to that situation, as described by Miller and Ireland (2005). EDM is developed in an authentic context through authentic activities and the ultimate goal is for the CQS to perform it expertly. The CQS gained multiple perspectives of expert performance to perform EDM with intuition. In their professional practice, the CQS undergoes coaching by a superior, which is called Assisted Supervisory Training. This experience provides scaffolding for the CQS's expert performance of EDM over time, so EDM can be viewed as an integrated assessment. The findings show that the CQS as an expert, perform EDM without fear because they are always confident and have a strong sense of integrity.

\section{References}

Abdul-Rahman, H., Hanid, M., \& Yap, X. W. (2013). Does professional ethics affect quality of construction - a case in a developing economy? Total Quality Management \& Business Excellence, 25(3-4), 235-248. https://doi.org/10.1080/14783363.2013.776764

Adnan, H., Hashim, N., Mohd, N., Yusuwan, \& Ahmad, N. (2012). Ethical Issues in the Construction Industry: Contractor's Perspective. Procedia - Social and Behavioral Sciences, 35(35), 719727. https://doi.org/10.1016/j.sbspro.2012.02.142

Bechara, A., \& Martin, E. M. (2004). Impaired Decision Making Related to Working Memory Deficits in Individuals with Substance Addictions. Neuropsychology, 18(1), 152-162. https://doi.org/10.1037/0894-4105.18.1.152

Browne-Ferrigno, T., \& Muth, R. (2006). Leadership mentoring and situated learning: catalysts for principalship readiness and lifelong mentoring. Mentoring \& Tutoring: Partnership in Learning, 14(3), 275-295. https://doi.org/10.1080/13611260600635530

Chamikara, P. B. S., Perera, B. A. K. S., \& Rodrigo, M. N. N. (2018). Competencies of the quantity surveyor in performing for sustainable construction. International Journal of Construction Management, 1-15. https://doi.org/10.1080/15623599.2018.1484848

Christabel, H. M.-F., \& Vincent, N. C.-W. (2003). Quantity surveyors' background and training, and their ethical concepts, conceptions and interests considerations. Construction Management and Economics, 21(1), 43-67.

https://doi.org/10.1080/0144619032000065117

Construction Industry Review Committee. (2001). Construct for excellence: report of the Construction Industry Review Committee. Construction Industry Review Committee.

Creswell, J. W., \& Poth, C. N. (2018). Qualitative inquiry \& research design: Choosing among five approaches (4th ed.). Sage.

Crosson, M., Mazutis, D., \& Seijts, G. (2013). In Search of Virtue: The Role of Virtues, Values and Character Strengths in Ethical Decision Making. Journal of Business Ethics 113(4) DOI:, 113(4). https://doi.org/10.1007/s10551-013-1680-8

Dall'Alba, G., \& Sandberg, J. (2006). Unveiling Professional Development: A Critical Review of Stage Models. Review of Educational Research, 76(3), 383-412.

https://doi.org/10.3102/00346543076003383

Dane, E., \& Pratt, M. G. (2007). Exploring Intuition and its Role in Managerial Decision Making. Academy of Management Review, 32(1), 33-54. 
INTERNATIONAL JOURNAL OF ACADEMIC RESEARCH ECONOMICS AND MANAGEMENT SCIENCES

Vol. 10, No. 3, 2021, E-ISSN: 2226-3624 @ 2021 HRMARS

https://doi.org/10.5465/amr.2007.23463682

Dreyfus, H. L., \& Dreyfus, S. E. (1986). Competent systems: The only future for inference-making computers. Future Generation Computer Systems, 2(4), 233-243.

https://doi.org/10.1016/0167-739x (86)90023-3

Egan, T. M. (2001). Organization Development: An Examination of Definitions and Dependent Variables. St Paul: Human Resource Development Research Center.

Eraut, M. (2000). Non-formal learning and tacit knowledge in professional work. British Journal of Educational Psychology, 70(1), 113-136. https://doi.org/10.1348/000709900158001

Eweje, G., \& Brunton, M. (2010). Ethical perceptions of business students in a New Zealand university: do gender, age and work experience matter? Business Ethics: A European Review, 19(1), 95-111. https://doi.org/10.1111/j.1467-8608.2009.01581.x

Garvey, B., Stokes, P., \& Megginson, D. (2018). Coaching and mentoring: theory and practice. Sage.

Ahma, K. H. (2012). Construction economics: problems and solutions. 2. Pearson Malaysia.

Kimble, C., Hildreth, P. M., \& Bourdon, I. (2008). Communities of practice: creating learning environments for educators. Information Age Pub., Cop. http://dro.deakin.edu.au/view/DU:30016985

Latham, G. P., \& Whyte, G. (1994). The Futility of Utility Analysis. Personnel Psychology, 47(1), 31-46. https://doi.org/10.1111/j.1744-6570.1994.tb02408.x

Lave, J., \& Wenger, E. (1991). Situated Learning Legitimate Peripheral Participation. Cambridge University Press.

Le, P. L., Elmughrabi, W., Dao, T.-M., \& Chaabane, A. (2018). Present focuses and future directions of decision-making in construction supply chain management: a systematic review. International Journal of Construction Management, 1-20.

https://doi.org/10.1080/15623599.2018.1488089

Lee, C. K., \& Foo, M. Y. (2020). Risk attitudes and the big five personality traits: a study on construction project practitioners in Malaysia. International Journal of Construction Management, 1-11. https://doi.org/10.1080/15623599.2020.1793506

Man-Fong Ho, C. (2011). Ethics management for the construction industry. Engineering, Construction and Architectural Management, 18(5), 516-537. https://doi.org/10.1108/09699981111165194

Mason, J. (2009). Ethics in the construction industry: the prospects for a single professional code. International Journal of Law in the Built Environment, 1(3), 194-204. https://doi.org/10.1108/17561450911001252

Merriam, S. B., \& Tisdell, E. J. (2016). Qualitative research: a guide to design and implementation. Jossey-Bass, Cop.

Meyers, C. (2004). Cruel Choices: Autonomy and Critical Care Decision-Making. Bioethics, 18(2), 104-119. https://doi.org/10.1111/j.1467-8519.2004.00384.x

Miller, C. C., \& Ireland, R. D. (2005). Intuition in strategic decision making: Friend or foe in the fast-paced 21st century? Academy of Management Perspectives, 19(1), 19-30. https://doi.org/10.5465/ame.2005.15841948

Mills, A. (2001). Developments in OMVPE. III-vs Review, 14(4), 50-53. https://doi.org/10.1016/s0961-1290 (01)80183-6 
Mukumbwa, B., \& Muya, M. (2013). Ethics in the Construction Industry in Zambia. International Journal of Construction Management, 13(2), 43-65. https://doi.org/10.1080/15623599.2013.10773211.

O'Leary, C., \& Stewart, J. (2007). Governance factors affecting internal auditors' ethical decisionmaking. Managerial Auditing Journal, 22(8), 787-808. https://doi.org/10.1108/02686900710819643

Transparency International. (2019). Corruption perceptions index 2018. Transparency International.

Valentine, S. R., Rittenburg, T. L. (2007). The Ethical Decision Making of Men and Women Executives in International Business Situations. Journal of Business Ethics 71, 125-134. https://doi.org/10.1007/s10551-006-9129-y

Wenger, E. (1999). Communities of practice. Cambridge Univ. Press.

Woiceshyn, J. (2011). A Model for Ethical Decision Making in Business: Reasoning, Intuition, and Rational Moral Principles. Journal of Business Ethics, 104(3), 311-323. https://doi.org/10.1007/s10551-011-0910-1

Yap, J. B. H., Lee, K. Y., Rose, T., \& Skitmore, M. (2020). Corruption in the Malaysian construction industry: investigating effects, causes, and preventive measures. International Journal of Construction Management, 1-12. https://doi.org/10.1080/15623599.2020.1728609 